\title{
Outcome of Obstructed Labour in Kano, Nigeria
}

\author{
Omole-OhonsiAbiodun', Belga Francis ${ }^{2}$ \\ Dept of Obs / Gyn, Bayero University/Aminu Kano Teaching Hospital', \\ Dept of Obs / Gyn, Murtala Mohammed Specialist Hospital2, \\ Kano, Nigeria.
}

\begin{abstract}
Aims: To study the sociodemographic characteristics, management options and obstetric outcome of obstructed labour at Aminu Kano Teaching Hospital, Kano, Nigeria.

Methods: A prospective study of obstructed labour cases that were managed between $1^{\text {st }}$ January 2002 and $31^{\text {st }}$ December 2006 was carried out. The study variables of interest were maternal age and parity, booking and educational statuses, causes, type of procedure that was used, and feto-maternal outcome. The data obtained were recorded using tables, histograms, and pie chart. Statistical analysis was done using chi-square test $\left(x^{2}\right)$, and a P-value of $<0.05$ was regarded as significant.

Results: The prevalence of obstructed labour was $0.8 \%$. The highest frequency was found among unbooked primigravid teenagers, who had Qu'ranic education only. The commonest cause was cephalopelvic disproportion (76.5\%). Lower segment caesarean section (LSCS) was performed in 72.5\%, while destructive operation was in $27.52 \%$. Regional anaesthesia was used in $74.5 \%$, while $25.5 \%$ were under general anaesthesia. The risk of developing complications did not show statistically significant difference between LSCS and destructive operation. Maternal mortality was $1.0 \%$ and perinatal mortality $52.9 \%$.
\end{abstract}

Conclusions: Obstructed labour is still common in our environment. With increased use of regional anaesthesia, LSCS and destructive operation were found to be safe, and the risk of complications was not different between the two procedures. Selection of patients for LSCS or destructive operations should be individualized,

Keywords: Obstructed labour, incidence, sociodemograhic characteristics, management options, fetomaternal outcome.

\section{Introduction}

Obstructed labour, which is the failure of the presenting part to descend in spite of adequate uterine contractions is one of the most common preventable causes of maternal and perinatal morbidity and mortality, especially in developing countries, where it accounted for $2-11 \%$ of maternal deaths ${ }^{1-3}$. Its occurrence is regarded as a sign of poor level of obstetric practice in any environment ${ }^{4}$, because obstructed labour is due to mechanical difficulties in labour, which is not recognized early because of poor supervision ${ }^{5,6}$. This is common in developing countries where proper obstetric care is not available or utilized $d^{7-10}$.
The frequency of obstructed labour in any community depends on the prevalence of cephalopelvic disproportion (CPD) and the quality of antenatal care $^{11-12}$. In our predominantly Islamic community in North West Nigeria, where early girl marriage and teenage pregnancies/grand multipara who are high risk for CPD are common, and more deliveries take place outside the hospitals attended by untrained midwives, obstructed labour is expected to be a common feature of our obstetric practice pr,13. $^{12}$.

No study has been carried out in our centre on this subject, and it is against this background that this study

Correspondence to:

Dr. Omole-Ohonsi A, FWACS

Senior Lecturer/ Consultant

Dept of Obs / Gyn

Bayero University/Aminu Kano Teaching Hospital,

Kano, Nigeria.

Tel no: 080-37870540s, P. O. Box 14578

Email:aomohoni@yahoo.com

General Post Office, Kano,Nigeria. 
was designed, to study the cases of obstructed labour in Aminu Kano Teaching Hospital, Kano, Nigeria, and to make recommendations which will reduce its incidence, influence the management policies, and feto maternal outcome in our institution, and other similar health facilities in developing countries.

\section{Methods}

A prospective study of obstructed labour cases that were managed at Aminu Kano Teaching Hospital, Kano, Nigeria, between $1^{\text {st }}$ January 2002 and $31^{\text {st }}$ December 2006 was carried out.

Aminu Kano Teaching Hospital is a tertiary health care delivery centre that is located in Kano City, the centre of commerce in Northern Nigeria and the capital of predominantly Islamic Kano State, where early girl marriage is not uncommon. Kano state has land area of 20,760 square Kilometers, and it is the most populous state in Nigeria, with a population of over ten million people (2006 Nigerian census). The health facility receives patients' referral from hospitals in the state, and neighboring states of Jigawa and Katsina.

At admission, the general condition of the mothers was assessed as well as the fetal lie, presentation, position and heart tones. Pelvic examination was carried out to assess the cervical dilatation, state of the liquor amnii, station and position of the presenting part, as well as the degree of caput and moulding. Uterine rupture was excluded by the presence of regular uterine contractions, minimal or absence of abdominal pain/ tenderness, and on vaginal examination by absence of vaginal bleeding and presenting part not displaced from the pelvic cavity.

Resuscitation of the mother was done with intravenous fluids and blood transfusion where necessary. Intravenous antibiotics were commenced, and continuous drainage of urine was carried out with an in-dwelling urinary catheter which was left in place for fourteen days post delivery. The obstruction was relieved by either lower segment caesarean section (LSCS) or by destructive operation (all were craniotomy).

The inclusion criteria for LSCS were all cases (1) with live fetus (2) with severely contracted pelvis (true conjugate less than $9.0 \mathrm{~cm})^{14}$, (3) impending uterine rupture, and(4) transverse lie with a live or dead fetus, while for destructive operation were cases (1) with dead fetus and full cervical dilation(2) where the true conjugate was $\geq 9.0 \mathrm{~cm}$, (3) where there was no impending uterine rupture or (4) transverse lie. Paediatricians were in attendance to resuscitate the live babies. Apgar score at 5 minutes of 7 and above was taken as normal, while scores less than 7 was taken as birth asphyxia ${ }^{15}$. Babies with birth asphyxia were transferred to the special care baby unit (SCBU) for further management.

The study variables of interest were maternal age and parity, booking and educational statuses, the causes, type of procedure that was used to relieve the obstruction, and feto-maternal morbidity and mortality.

The data were prospectively obtained from the women using a pre-designed proforma, and were expressed as frequencies, percentages, mean and standard deviation and recorded in tabular forms, histograms and Pie Chart. Statistical analysis was done using Epi- Info software (6.0 CDC Atlanta Georgia, USA). Chisquare test was used for comparison of the data for statistical significance. A p-value of $<0.05$ was taken as significant.

\section{Results}

The total number of deliveries during the period of study was 12,954 , obstructed labour accounted for 102 cases, giving an incidence of $0.8 \%$. LSCS was performed in 74 cases $(72.5 \%)$, while destructive operation was in 28 cases $(27.5 \%)$. Regional anaesthesia (spinal anaesthesia only) was used in 76 cases $(74.5 \%)$, while $26(25.5 \%)$ were under general anaesthesia. Among those who had LSCS, regional anaesthesia was used in 48 cases $(64.9 \%)$, while 26 cases $(35.1 \%)$ were under general anaesthesia. All the destructive operations were done under regional anaesthesia. There were 40 patients with intrauterine fetal death; destructive operation was performed in 28 cases $(70 \%)$, while LSCS was used in $12(30 \%)$ cases. All the patients (62) with live babies had LSCS.

Among the patients 98 (96.1\%) were unbooked, while $4(3.9 \%)$ were booked. The odd of having obstructed labour was times 600 times higher among unbooked patients $(\mathrm{OR}=600.25,126.35-3457.89, \mathrm{P}<0.05)$. Majority of the patients $89(87.3 \%)$ had Qu'ranic education only, while $13(12.7 \%)$ had western education. The odd having of obstructed labour was 46 times higher among patients who had only Qu'ranic education $(\mathrm{OR}=46.87,19.23-117.66, \mathrm{P}<0.05)$.

The highest frequency was found among the teenagers and the least among those $\geq 40$ years of age. The mean age was $20.7 \pm 9.0$ years. Age distribution showed a bimodal trend with the first peak among the teenagers and the second among those $30-39$ years of age. The method of management of the patients according to age groups showed that the highest frequency of LSCS and destructive operation was found among the teenagers, and the least among those $\geq 40$ years of age. LSCS showed a bimodal trend, with the first peak among the 
teenagers, and the second among those 30-39 years of age, while destructive operation showed a linear trend with the frequency of the procedure decreasing with increasing age.

\section{Fig 1. Age and Management Distribution}

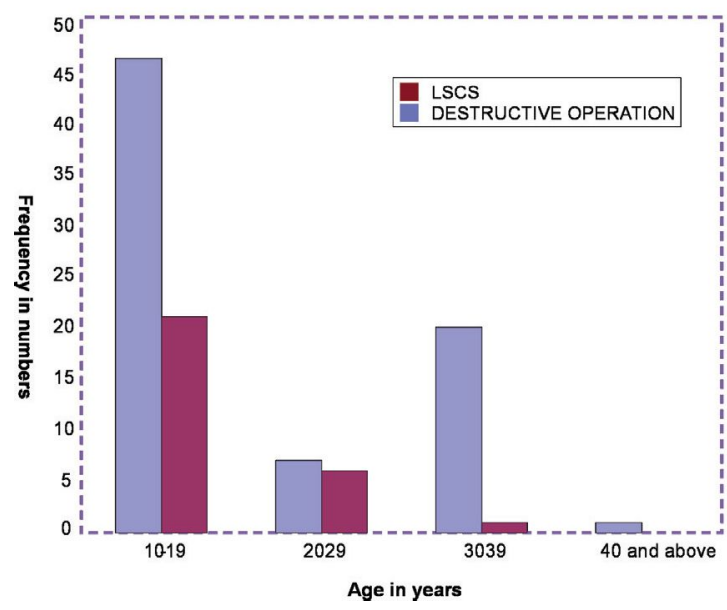

The highest frequency was found among primigravidae, while the least was among multigravidae. The mean parity was $2.3 \pm 3.6$. The distribution according to parity showed a bimodal trend, with the first peak among primigravidae and the second among the grandmultiparae. Management of the cases according to parity also showed that the highest frequency of LSCS and destructive operation were found among the primigravidae. The least frequency of LSCS was found among multigravidae, while for destructive operation it was among the grandmultiparae.

Fig 2. Parity and Management Distribution

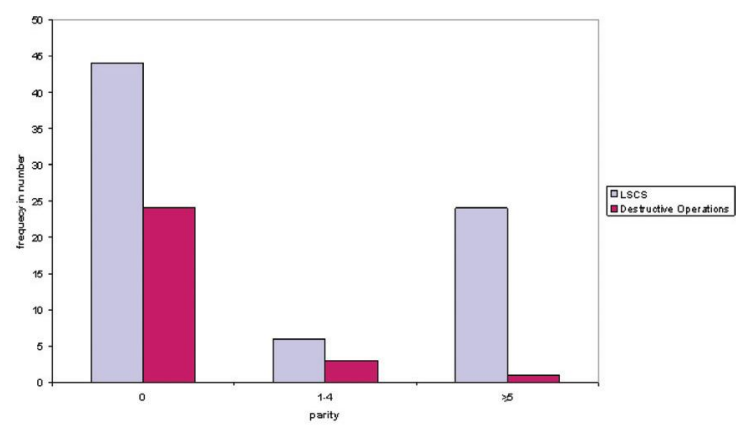

CPD (78) was responsible for $76.5 \%$ of the cases. Malposition (persistent occipito-posterior (14) 13.7\%, and malpresentation, transverse lie (10)9.8\%.

Normal Apgar Score was found in $23.5 \%$ of the babies, while $37.3 \%$ had birth asphyxia, and 27.5\% had neonatal sepsis. Among the women 39.2\% had intrauterine fetal death. Immediate neonatal death occurred in $13.7 \%$ of the babies and perinatal mortality was $52.9 \%$.
Fig 3. Causes of obstructed labour

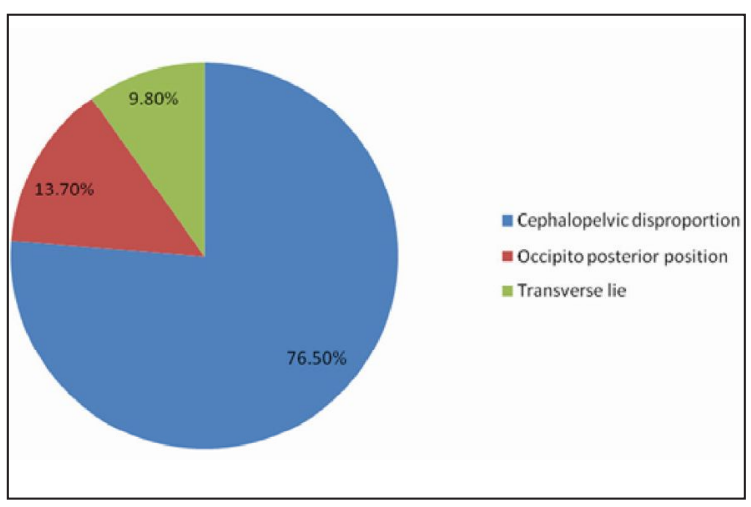

Table 1. Fetal outcome

\begin{tabular}{lc} 
Fetal outcome & Frequencyn(\%) \\
\hline Normal Apgar Score & $24(23.5)$ \\
Birth Asphyxia & $38(37.3)$ \\
Neonatal Sepsis & $28(27.5)$ \\
Intrauterine Fetal Death & $40(39.2)$ \\
Immediate Neonatal Death & $14(13.7)$ \\
Perinatal Mortality & $54(52.9)$ \\
Total & $\mathbf{1 0 2 ( 1 0 0 )}$ \\
\hline
\end{tabular}

Table 2. Maternal outcome and route of delivery

$\begin{array}{ccc}\begin{array}{l}\text { Maternal Complications } \\ \mathbf{n}=74\end{array} & \text { LSCS } & \begin{array}{c}\text { Destructive } \\ \text { Operation }\end{array} \\ & & \begin{array}{c}\text { Ppe Value } \\ \end{array} \\ \end{array}$

$\begin{array}{lcc}\begin{array}{l}\text { Asherman's Syndrome } \\ \text { Puerperal Sepsis }\end{array} & \begin{array}{l}1 \mathrm{P}>0.05(\mathrm{~N} / \mathrm{S}) \\ \text { Primary Postpartum }\end{array} & 5 \mathrm{P}>0.05(\mathrm{~N} / \mathrm{S}) \\ \begin{array}{l}\text { Haemorrhage } \\ \text { Urinary Tract Infection }\end{array} & 10 & 4 \mathrm{P}>0.05(\mathrm{~N} / \mathrm{S}) \\ \begin{array}{l}\text { Intra-operative bladder Injury } \\ \text { (N/S) }\end{array} & 4-\mathrm{P}>0.05 \\ \begin{array}{l}\text { Maternal Death } \\ \text { (N/S) }\end{array} & -1-\mathrm{P}>0.05 \\ \end{array}$

$\mathrm{N} / \mathrm{S}=$ Not statistically significant 
The incidence of each complication did not show any statistically significant difference among those who had LSCS and destructive operation. The only maternal death was an unbooked patient who came in moribund and had LSCS under general anaesthesia. Table 2.

There was no case of vesico-vaginal fistula or rectovaginal fistula. Five patients had vaginal laceration among those who had craniotomy, while 12 patients had wound sepsis among those who had LSCS. They were all treated with antibiotics. Those with vaginal laceration had primary repair, while those with abdominal wound sepsis were discharged home on daily wound dressing in the general out-patient department, and secondary repair was done where necessary. The duration of hospital stay was 14 days in the two groups.

\section{Discussion}

The prevalence of $0.8 \%$ for obstructed labour in this study is comparable to that in recent studies ${ }^{8,16}$, but it is lower than $2-5 \%$ from earlier studies from developing countries $^{2,5,7,17}$. This probably reflects improvements in provision and utilization of antenatal care facilities and early presentation in labour.

Age and parity distribution showed a bimodal trend in the frequency of obstructed labour, probably because early girl marriages which are associated with teenage pregnancies and grandmultiparity, which themselves are risk factors for CPD, are common in our society, and may account for why CPD was the commonest cause in this study. This was also the experience of other authors from developing countries ${ }^{11,13}$.

The frequency of destructive operation decreased with increasing age and parity, probably because primgravid uterus unlike that of multigravida, meet obstruction in labour with uterine inertia, which makes them more suitable for destructive operation ${ }^{8,16,18,19}$. This concurs with the findings of other authors ${ }^{8,16}$.

Most of the patients were unbooked and had Qur'anic education only, probably because lack of western education has been associated with aversion to western oriented programs like antenatal care and hospital delivery $^{3}$.

All the destructive operations performed were craniotomy, which does not agree with other studies ${ }^{8}$, probably because decapitation and evisceration may not be acceptable in our community for sociocultural reasons. Studies from developing countries showed that in their hospital, destructive operations were avoided because of its high association with complications ${ }^{16}$. This calls for proper training in the use of destructive operations in our Medical schools, especially in developing countries, where majority of cases of obstructed labour with intrauterine fetal deaths are common, and the women may not present in the hospital in subsequent pregnancies and deliveries, because of aversion to caesarean section.

Destructive operation was contraindicated in women with true pelvic conjugate of less than $9.0 \mathrm{~cm}$, because studies from Nigeria found it to be the point below which severe pelvic contraction is diagnosed ${ }^{14}$. This does not agree with studies from India ${ }^{8}$, where severe pelvic contraction was found to be $7.8 \mathrm{~cm}$ or less. This has been attributed to the smaller size of the Indian women' ${ }^{9}$ With severe pelvic contraction, after decompression of the head and crushing of the base of the skull, the reduction in the diameter of the fetal head may not be enough to allow it to be delivered vaginally, and recourse to caesarean section may be required ${ }^{20}$.

Maternal mortality rate of $1.0 \%$ in this study, where LSCS $(72.5 \%)$ and destructive operation $(27.5 \%)$ were done using mainly regional anaesthesia $(74.5 \%)$, is lower than 4\% that was reported from Enugu in South Eastern Nigeria, where LSCS (85\%) and destructive operation (10\%), and 3.7\% from Ethiopia where LSCS (46.1\%) and destructive operation (16.2\%) were carried out using mainly general anaesthesia ${ }^{7}$. Increased use of regional anaesthesia in this study may have made the difference, because regional anaesthesia has been found to make LSCS to be safe, and its outcome to be comparable to that of destructive operation even in moribund cases ${ }^{8}$. This may explain why the risk of developing maternal complications with either LSCS or destructive operation was not different in this study, which was also the experience of other authors ${ }^{8}$ in studies where regional anaesthesia was used in majority of the cases.

Perinatal mortality of $52.9 \%$ in this study is similar to that of other studies from developing countries ${ }^{2,6,9}$. The poor perinatal outcome which has been attributed to intrauterine hypoxia/ birth asphyxia and neonatal sepsis, from delay in presentation in the hospital and prolonged labour ${ }^{2,3}$, calls for urgent intervention to make health care delivery services accessible and affordable, and also to train Traditional Birth Attendants (TBAs), especially in the use of partogram in labour management, which will make them to refer the patients early.

The duration of hospital stay was 14 days in the two groups, probably because the urethral catheter was left in-situ for 14 days post-operation, to rest the urinary bladder and prevent vesico-vaginal fistula. This, together with meticulous care, may explain why there was no case of vesico-vaginal fistula as reported by other authors ${ }^{8}$. 


\section{Conclusion}

CPD still remains the commonest cause of obstructed labour although there is decreasing trend of obstructed labour in our community. The highest frequency was found among unbooked, primigravid teenagers, who had only Qu'ranic education.

With increased use of regional anaesthesia, maternal mortality rate was low, and both procedures appear safe. The incidence of complications was not different between LSCS and destructive operation; hence the choice of method of delivery between LSCS and destructive operation should be individualized. Regional anaesthesia, destructive operations and symphysiotomy which in trained hands are easy to perform, and associated with minimal complications, should be emphasized in our training curriculum. Destructive operation and symphysiotomy has the advantage of no uterine scar in the next pregnancy, while symphysiotomy has the added advantage of a larger pelvis in the next pregnancy, should be revisited in developing countries, where majority of the pregnant women are unbooked and poorly supervised in labour.

Female western education and care of the 'girl child', free or subsidized antenatal care and hospital delivery, and training of TBAs in the use of partogram in labour management, should be implemented in developing countries, if the incidence and complications of obstructed labour are to be reduced.

However, because of the biases inevitable in this hospital-based series and the small sample size, larger multicentre studies will be required to confirm these findings.

\section{References}

1 Gessessew A, Mesfin M. Obstructed labour in Adigrat zonal hospital, Tigray Region, Ethiopia. Ethiop J Health Dev 2004; 17 (3): 175-80.

2 Oronsanye AU, Asuen MI. Obstructed labour - a four year survey at the University of Benin Teaching Hospital, Benin City, Nigeria. Trop Doct 1980; 10:113-115

3 Harrison KA. Child bearing, health and social priorities. A survey of 22,744 consecutive hospital births in Zaria, Northern Nigeria. Br J Obstet Gynaecol 1985; 92(Suppl 5):1-119

4 Maternal mortality situation and determinants in Nigeria. FMOH 2004.
5 Konje JC. Obisesan KA, Ladipo OA. Obstructed labour in Ibadan. Int J Gynaecol Obstet 1992; 39:17-21.

6 Daffallah SE, Ambago J, El-Agib F. Obstructed labour in a teaching hospital in Sudan. Saudi Med J 2003; 24:1102-1104

7 Ozumba $\mathrm{BC}$, Uchegbu $\mathrm{H}$. Incidence and management of obstructed labour in Eastern Nigeria. Aust N Z J Obstetric Gynaecol 1991; 31:213-216

8 Adhikari S, Dasgupta M, Sanghamita M. Management of obstructed labour: a retrospective study. J Obstet Gynaecol Ind 2005; 55(1):4851

9 Konje JC, Ladipo OA. Nutrition and obstructed labour. Am J Clin Nutri.2000; 72(1):291S297S

10 Moller B. Lindmark G. Short stature: an obstetric risk factor? A comparison of two villages in Tanzania. Acta Obstet Gynaecol Scand 1997; 76:394-397

11 Omole-Ohonsi A, Ashimi OA. Maternal mortality review in Aminu Kano Teaching Hospital, Kano - Northern Nigeria. Nigerian Journal of Basic and Clinical Science 2006; 3 (1-2): 10-16.

12 Omole-Ohonsi A, Belga Y.Emergency Obstetric Hysterectomy. Archives of Nigerian Medicine and Medical Sciences 2007; 4(2): 16-22.

13 Jesse Y, Obed A, Mairiga. Outcome of subsequent labour after primary caesarean section for arrest disorders in teenage pregnancies. Trop J Obstet Gynaecol 2004; 21(1):36-39

14 Makanjuola D, Ayangade O. A study correlating antenatal pelvimetry with the outcome of labour in Nigerian woman. Afr J Me 2004; 3(3): 143

15 National Clinical Service Protocol for Obstetric and Neonatal Care. FMOH Nigeria 2006; 317

16 Rather S Y, Qureshi A, Parveen D O Obstructed labour - Current scenario in a developing country. Internet J Gynae Obstet 2010; 13(2).

17 Naeye RL, Dozor A, Tafari N, Ross SM. Epidemiological features of perinatal death due to obstructed labour in Addis Ababa. Br J Obstet Gynacol 1977; 84:747-750

18 Dutta DC. Destructive operations in obstructed labour. J Indian Med Assoc 1979; 72:204-206

19 Gupta U, Chitra R. Destructive operations still have a place in developing countries. Int $\mathrm{J}$ Gynaecol Obstet 1994, 44:15-19.

20 Omole-Ohonsi A. Craniotomy. Instruments in Obstetrics and Gynaecology. Hamza publications. Kano 2004. pp: 10-14. 